\title{
VESTIBOLOGY
}

\section{Evaluation of a large cohort of adult patients with Ménière's disease: bedside and clinical history}

\author{
Sindrome di Ménière: valutazione dell'esame vestibolare e della storia clinica \\ in un'ampia popolazione
}

\author{
Roberto Teggi1,2, Rosa Alessia Battista ${ }^{1,2}$, Federica Di Berardino ${ }^{3}$, Marco Familiari ${ }^{1,2}$, lacopo Cangiano², Omar Gatti ${ }^{1}$, \\ Mario Bussi ${ }^{1,2}$ \\ ${ }^{1}$ Department of Otolaryngology Head \& Neck Surgery, IRCCS San Raffaele Scientific Institute, Milan, Italy; ${ }^{2}$ Vita-Salute San \\ Raffaele University, Milan, Italy; ${ }^{3}$ Audiology Unit, Dept of Clinical Sciences and Community Health and Dept. of Specialistic Surgical \\ Sciences, Fondazione IRCCS Cà Granda, Ospedale Maggiore Policlinico, University of Milan, Italy
}

\begin{abstract}
SUMMARY
Objective. The purpose of this study was to assess vestibular findings and clinical history in a large cohort of patients affected by Ménière's disease.

Methods. We retrospectively analysed 511 adult patients fulfilling criteria for definite unilateral Ménière's disease according to Barany Society. Thorough clinical history, audiometric exam, central nervous system MRI, quantification of serum autoantibodies and complete vestibular function test were performed.

Results. Mean age at clinical record was 55.4 years, while age at onset of the first vertigo attack was $47.4 \pm 14.3$ years. Ménière's disease overlapped with migraine in $43.4 \%$ of patients. In $31.7 \%$ of cases, positivity was found for at least one autoantibody. Forty-nine patients $(9.6 \%)$ had family history for Ménière's disease. Bedside examination resulted in $14.7 \%$ positivity for video head impulse test, $58.9 \%$ for skull vibration-induced nystagmus, $38.7 \%$ for the positional test and $23.1 \%$ for the post head shaking test. Complete negative examination was reported in 115 cases.

Conclusions. Ménière's disease was seen to present a characteristic phenotypic pattern in our cohort, confirming the crucial role of thorough anamnesis and bedside examination in diagnosis.
\end{abstract}

KEY WORDS: Ménière's disease, migraine, autoimmunity, family history, vestibular function tests

\section{RIASSUNTO}

Obiettivo. Analizzare un'ampia casistica di pazienti affetti da sindrome di Ménière con particolare attenzione al dato anamnestico ed ai test di funzione vestibolare.

Metodi. Sono stati raccolti retrospettivamente i dati di 511 pazienti affetti da sindrome di Ménière monolaterale definita, che soddisfacevano i criteri della Barany Society. Ogni paziente è stato sottoposto a raccolta anamnestica, esame audiometrico tonale, RM encefalo, test di autoimmunità ed esame otovestibolare.

Risultati. L'età media alla presentazione clinica è stata di 55,4 anni mentre l'età del primo episodio di vertigine è risultata essere 47,4 \pm 14,3. Il 43,4\% della popolazione soffre contestualmente di emicrania. Nel 31,7\% dei casi è stata quantificata una positività di almeno un autoanticorpo. Quarantanove pazienti hanno riferito un familiare affetto da possibile sindrome di Ménière. La video head impulse è risultata positiva nel 14,7\%, il test vibratorio nel 58,9\%,38,6\% il test posizionale nel 38,7\% e la HST nel 23,1\%; una completa negatività ai test vestibolari è stata rilevata in 115 casi.

Conclusioni. La sindrome di Ménière è spesso associata ad un fenotipo clinico e strumentale suggestivo che conferma il ruolo cruciale di una attentata raccolta anamnestica e dell'esame vestibolare nella diagnosi.

PAROLE CHIAVE: sindrome di Ménière, emicrania, autoimmunità, familiarità, esame vestibolare
Received: April 2, 2020

Accepted: July 16, 2020

Correspondence

Roberto Teggi

San Raffaele Hospital, via Olgettina 60, 20132

Milan, Italy

Tel. +3902 26433522. Fax +390226433508

E-mail: teggi.roberto@hsr.it

Funding

None.

Conflict of interest

The Authors declare no conflict of interest.

How to cite this article: Teggi R, Battista RA, Di Berardino F, et al. Evaluation of a large cohort of adult patients with Ménière's disease: bedside and clinical history. Acta Otorhinolaryngol Ital 2020;40:444-449. https://doi. org/10.14639/0392-100X-N0776

(C) Società Italiana di Otorinolaringoiatria e Chirurgia Cervico-Facciale

\section{(c) $($ ) $\$$}

This is an open access article distributed in accordance with the CC-BY-NC-ND (Creative Commons Attribution-NonCommercial-NoDerivatives 4.0 International) license. The article can be used by giving appropriate credit and mentioning the license, but only for non-commercial purposes and only in the original version. For further information: https:// creativecommons.org/licenses/by-nc-nd/4.0/deed.en 


\section{Introduction}

Ménière's disease (MD) is an inner ear disorder characterised by episodic vertigo, usually preceded by cochlear symptoms: fluctuating hearing loss, tinnitus and aural fullness ${ }^{1}$. Increased endolymphatic volume (hydrops) is the commonly accepted pathophysiological mechanism, and this finding is also supported by newly developed imaging techniques ${ }^{2,3}$. However, the aetiology of the disorder is not fully understood. Recent publications have focused on the possibility of differentiating subgroups of unilateral MD subjects characterised by specific clinical features ${ }^{4}$. Moreover, since 8-9\% of MD patients have positive family history ${ }^{4}$, this highlights the possibility to develop new biomarkers including genetic ones ${ }^{5,6}$.

Currently, diagnosis mainly relies on clinical history and audiometric exam; in 2015, the Barany Society proposed the following diagnostic criteria for definite MD ${ }^{7}$.

A. Two or more spontaneous episodes of vertigo each lasting 20 minutes to 12 hours.

B. Audiometrically documented low to medium frequency sensorineural hearing loss in one ear, defining the affected ear, on at least one occasion before, during, or after one of the episodes of vertigo.

C. Fluctuating aural symptoms (hearing, tinnitus or fullness) in the affected ear.

D. Not better accounted for by another vestibular diagnosis.

MD presents in association with two other conditions: migraine and autoimmune disorders. In fact, around $50 \%$ of MD patients also suffer from migraine ${ }^{8}$, and proteomics studies support the possibility of autoimmunity as a potential mechanism predisposing to MD ${ }^{9}$.

Audiometric exam is mandatory for diagnosis of MD, while few studies have been published on vestibular findings during bedside examination. The purpose of the present study was to assess clinical history and vestibular findings in MD patients with 4 tests, namely Video Head Impulse Test (Video-HIT), Head Shaking Test (HST) and positional and Skull Vibration Test, performed outside attacks of vertigo.

\section{Materials and methods}

\section{Study cohort}

In our retrospective study the sample was composed of 511 adult patients; data were obtained from records of patients from 2008 to 2019 . The study received ethical approval by an internal committee (No. GO/URC/ER/mm prot 762). Patients were included if they fulfilled criteria for definite unilateral MD according to the Barany Society; in subjects enrolled before 2015 a retrospective analysis of data confirmed Barany criteria ${ }^{7}$. Evaluation was made in a vertigo- free period (at least 15 days from the last vertigo attack). At inclusion all patients presented unilateral MD, while during different follow-up 21 (4.1\%) of them developed bilateral MD.

Clinical history was collected with particular attention to migraine. According to International Headache Society (HIS) criteria ${ }^{10}$, migrainous headaches typically last between 4 and $72 \mathrm{~h}$ and present at least two of the following features:

- unilateral;

- pulsating;

- moderate or severe intensity of pain;

- aggravated by, or resulting in the avoidance of, routine physical activity.

All patients underwent audiometric exam confirming a low to middle frequencies gap between the two thresholds in at least 2 frequencies, and concomitant vestibular evaluation, as routinely done in outpatients presenting for vertigo. Data were stored in a protected database. Cases were excluded if surgically treated before the examination or if they had undergone intratympanic therapy with steroids or gentamicin; delayed hydrops were not included. All subjects underwent central nervous system MRI with contrast focused on the cerebello-pontine angle to rule out 8th nerve schwannoma. All subjects were asked to assess autoimmunity with a panel of anti-nucleus (which were considered positive when with a title at least of 1:160), anti-neutrophil cytoplasmic, anti-thyroids and anti-cardiolipin autoantibodies.

One-hundred and fifty-five patients were also included in another genetic study on MD ${ }^{11}$.

\section{Bedside vestibular examination}

Nystagmus was studied with video Frenzel goggles (Interacoustics - Assens - Denmark); spontaneous nystagmus was assessed with the patient seated in a clinical chair, in primary position and eyes rotated $15^{\circ}$ on the right and left side. Positional nystagmus was assessed in the supine position with the head turned $90^{\circ}$ on both sides.

Post head shaking test (HST) was performed with the patient sitting in a clinical chair with the head leaning down by $30^{\circ}$; nystagmus was studied with video Frenzel goggles. The patient's head was vigorously rotated for 20 times on the horizontal plane with a maximum amplitude around 30$40^{\circ}$. Post HST nystagmus was recorded for 1 minute and was considered positive when nystagmus lasting at least 5 seconds was detected.

Skull vibration test (Skull Vibration Induced Nystagmus SVIN) was performed at $100 \mathrm{~Hz}$ with a commercially available system (VVIB - Synapsis). Stimuli were applied perpendicularly to the skin over the mastoid process, posteriorly to the auricle, at the level of the external acoustic meatus with 
a force around $1 \mathrm{~kg}$; three stimulation trials were performed on each mastoid, lasting 5-10 seconds each. Eye movements were studied with video Frenzel goggles and visual fixation of both eyes was inhibited. The test was considered positive when a horizontal nystagmus, always beating on the same side, was elicited in all 6 trials; it was considered "paretic" when directed toward the healthy side, and "irritative" when beating toward the affected side ${ }^{12}$.

Video head impulse test (video-HIT) was performed only on the horizontal plane with a commercially available system (ICS Impulse, Otometrics, Taastrup, Denmark). Subjects were asked to remove spectacles at least 5 minutes before examination and calibration was made before tests. The calibration was also checked in the horizontal canal plane with slow sinusoidal movement of the head while the patient was asked to fixate the target. In this way, at least at low head velocity, we could confirm that head-eye velocity traces were overlapping and minimised the risk linked to the presence of square waves. Trials with blinks and outliers were automatically excluded. Patients in whom recordings demonstrated that eye movements always preceded head movements, even after attempts to improve goggle fit, were not included ${ }^{13}$. We considered the exam pathological when VOR gain was lower than 0.80 and/or when corrective saccades were demonstrated, while normal values were detected on the contralateral side.

All procedures were performed by a senior neurotologist.

\section{Statistical analysis}

Quantitative variables are presented as mean \pm standard deviation and categorical as rate on the total sample. A P value $<0.05$ was considered statistically significant. Spearman's test was performed to investigate the association between different variables. A linear regression model was calculated to assess the independent role of migraine, autoimmunity and family history on age of onset of vertigo; a linear regression was also performed to assess the independent role of age and duration of the disorder on different clinical signs. Chi-square and odds ratio were calculated to establish the different frequencies of clinical signs in subjects with and without a comorbidity for migraine and autoimmune disorders. We used SPSS software version 22.0 (SPSS, Inc., Chicago, IL, USA) for statistical analyses.

\section{Results}

\section{Study population}

In our cohort of $511 \mathrm{MD}$ patients, $260(50.8 \%)$ were females. Mean age at presentation was $55.4 \pm 14.1$ years (range 18-86) and age at first vertigo attack was $47.4 \pm 14.3$ years. Duration (the period between the first vertigo attack

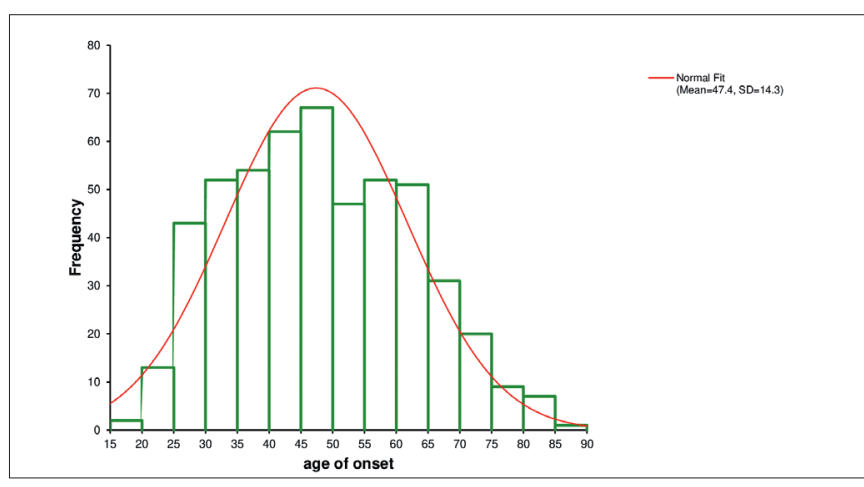

Figure 1. Age of onset of the first vertigo attack.

and inclusion) of disease was $8.3 \pm 8.1$ years. The distribution of age of the first vertigo in the sample is summarised in Figure 1. All patients reported several vertigo spells with nausea/vomiting; audiometric exam presented a hearing loss on low frequencies without differences between thresholds in 104 cases $(20.3 \%)$, while all other subjects presented a flat threshold in the diseased ear. Twenty-six patients $(5.1 \%)$ had positive history for Tumarkin attacks. The age of these subjects was higher than the entire sample $(71 \pm 5, \mathrm{p}<0.01)$. A Spearman test showed correlation with both patient age $\left(\mathrm{r}_{\mathrm{s}} 0.25, \mathrm{p}=0.0002\right)$ and duration of vertigo attacks $\left(\mathrm{r}_{\mathrm{s}} 0.18, \mathrm{p}=0.02\right)$.

\section{Comorbidities}

In this cohort, 222 (43.4\%) suffered from migrainous headache; 27 patients (12.1\% of migraineurs) referred visual aura. The onset of the first migrainous headache was $27 \pm 6.3$ years. In all subjects except 4 the headache preceded the onset of vertigo. Micro-ischaemic lesions were detected on central nervous system MRI in 123 patients (24\%).

Positivity for at least one autoantibodies was detected in 162 subjects (31.7\%). The most common autoimmune disorders were thyroiditis $(\mathrm{n}=65,12.7 \%)$, undifferentiated connective tissue disease $(\mathrm{n}=10,2 \%)$ and rheumatoid arthritis $(n=6,1.2 \%)$; in the remaining $81(16 \%)$ patients, positivity for autoantibodies was an occasional finding and patients did not report clinical signs of an autoimmune disorder; consultation with a rheumatologist was asked in all subjects. Positivity for at least one autoantibody was more represented in the sample of migraineurs $\left(\chi^{2} \mathrm{p}=0.001\right.$; odds ratio $0.53,95 \%$ CI $0.36-0.77$ ).

Forty-nine patients (9.6\%) had family history, and in 20 a first-degree relative reported episodic vertigo and hearing loss (mother/father or brother/sister).

A linear model demonstrated that both migraine and family history were predictive for earlier onset of the vertigo. The results are reported in Table I. 
Table I. Age of onset of the first vertigo attack according to different variables.

\begin{tabular}{lcccccc} 
& Coefficient & \multicolumn{2}{c}{$95 \%$ Cl } & SE & T Statistic & p \\
Migraine & -10.36 & -12.96 & to -7.76 & 1.323 & -7.83 & -2.44 \\
Family history & -4.997 & -9.022 & to -0.971 & 2.0490 & 0.0001 & -0.75 \\
Autoimmunity & -0.9883 & -3.5718 & to 1.5953 & 1.31501 & 0.4527 \\
Sex & -2.142 & -4.721 & to 0.436 & 1.3125 & -1.63 & 0.1032 \\
\hline
\end{tabular}

Data show a linear model considering the age of onset of vertigo as a dependent variable and migraine, family history and positivity for at least one autoantibody as independent variables. Cl: Confidence Interval; SE: Standard Error

\section{Bedside examination}

Positive video HIT was found in 75 patients (14.7\%), positive SVIN in $301(58.9 \%)$, positive positional test in 198 (38.7\%) and post HST in 118 (23.1\%); in 115 subjects all clinical signs were negative. Only 2 patients with positive SVIN demonstrated an "irritative" nystagmus beating toward the diseased ear. Patients with positive vestibular tests in the entire sample and in subsamples, according to comorbidities of migraine or autoimmune disorders, are reported in Table II. Among 198 patients with positive positional test, 169 showed a monopositional apogeotropic nystagmus turning the head on the affected side, while in 29 a bipositional apogeotropic nystagmus was detected; all were characterised by few/no latency, low frequency, long lasting nystagmus (more than 3 minutes) and no vertigo. When asked, patients did not refer positioning vertigo in the previous days, possibly related to benign paroxysmal positional vertigo. Statistical analyses demonstrated that positive positional tests $\left(\mathrm{n}=198, \chi^{2} \mathrm{p}=0.04\right.$; odds ratio $=1.43$, 95\% CI 1.00-2.05), as well as a bipositional apogeotropic nystagmus $\left(\mathrm{n}=19, \chi^{2} \mathrm{p}=0.0016\right.$; odds ratio $=2.6,95 \%$ CI 1.18-5.72,) were more frequent in migraineurs than in general sample. The duration of vertigo spells had no correlation with the clinical findings.

\section{Discussion}

Herein, we mainly focused on clinical history and comorbidities, specifically family history, migraine and autoimmunity (as routinely done in our centre), along with bedside examination.
We found an overlap between migraine and MD, demonstrated in $43.4 \%$ of MD subjects, while a recent study estimated the lifetime prevalence of migraine in general population to be around $10 \%{ }^{14}$. The association of MD and migraine is still under debate; in a previous work, this comorbidity was reported in $56 \%$ of MD subjects ${ }^{8}$. Further works revealed a lower rate of migraineurs ${ }^{4}$ or showed no association between the two disorders, even if the same author reported that symptoms suggestive of migraine may co-exist in patients with hydropic ear ${ }^{15}$.

In all, $9.6 \%$ of all cases referred family history, which is in accordance with previously reported data ${ }^{16,17}$; however, we investigated relatives with episodic vertigo and hearing loss and it was impossible to confirm that cases were at least probable MD.

Interesting data was also seen considering the autoimmunity spectrum. Positivity for at least one autoantibody was detected in $31.7 \%$ of the sample, even if an autoimmune disorder was diagnosed in only $15.9 \%$ of these patients, with thyroiditis being the most frequent. Positivity for a single autoantibody was more frequent in migraineurs. The observed value (15.9\%) of MD subjects with an autoimmune disorder is consistent with other published studies ${ }^{4}$, reported to be around 17\% in unilateral MD and over 20\% in bilateral MD ${ }^{18}$. Interestingly, the number of patients with positivity for at least one antibody was $31.7 \%$, which is lower than the previously reported percentage (38\%) by other authors for only anti-thyroid autoantibodies ${ }^{19}$. The association between inner ear disorders and vertigo has been widely studied in the last years and it should be underlined that autoimmunity has been proposed as a predis-

Table II. Bedside examination results in the entire cohort and subgroups.

\begin{tabular}{|c|c|c|c|c|}
\hline & $\begin{array}{l}\text { Total sample } \\
\quad(n=511)\end{array}$ & $\begin{array}{l}\text { Migraineurs } \\
(n=222)\end{array}$ & $\begin{array}{l}\text { Autoimmune }+ \\
\quad(n=162)\end{array}$ & $p$ \\
\hline Video - HIT & 75 (14.7\%) & 25 (11.3\%) & 23 (14.2\%) & n.s. \\
\hline SVIN & 301 (58.9\%) & $111(50 \%)$ & 94 (58\%) & n.s. \\
\hline Positional test & 198 (38.7\%) & $96(43.2 \%)$ & $67(41.3 \%)$ & n.s. \\
\hline Post HST & $119(23.1 \%)$ & $47(21.2 \%)$ & $36(22.2 \%)$ & n.s. \\
\hline
\end{tabular}

Total number and percentage of patients with positive vestibular tests (Video HIT: Video Head Impulse Test; SVIN: Skull Vibration Induced Nystagmus; HST; Head Shaking Test) in the total population and according to Migraineurs and patients with positivity for at least one of the autoantibodies (Autoimmune +). 
posing factor to develop MD; this hypothesis is supported by the fact that hydrops can be induced experimentally by injection of antigens or monoclonal antibodies and the deposition of circulating immune complexes may produce inflammation and interfere with the filtering capability of the endolymphatic sac ${ }^{20,21}$.

Interesting results can be obtained by clinical signs collected outside vertigo spells. We found a positive videoHIT in $14.7 \%$ of subjects. These results substantially confirm those of previous works, reporting low percentages of positive video HIT ranging between $54.5 \%{ }^{20}$ and $0 \%{ }^{22,23}$ in patients beyond vertigo attack. It can be speculated that video-HIT studies rapid vestibular acceleration, thus focusing on irregular neurons and phasic type-1 hair cells whose activity can be spared in hydrops ${ }^{24}$.

SVIN was seen to be a more sensitive test, provoking a consistent nystagmus beating toward the unaffected side in 301 patients (58.7) except for two cases in which the nystagmus direction was toward the hydropic side. SVIN is a newly proposed test that is able to reveal nystagmus in patients with asymmetry in vestibulo-oculomotor reflex. The slow phase velocity of SVIN seemed to be correlated with that of caloric tests, suggesting the possibility that skull vibration mainly concerns the horizontal canal ${ }^{12}$. Moreover, other authors demonstrated a correlation between SVIN and caloric tests when caloric hypofunction was higher than $50 \%{ }^{25}$. Finally, it has been reported that vibration on mastoid or neck muscles induced a shift of the subjective visual vertical, suggesting an induced deficit of the otolithic organs or vertical semicircular canals ${ }^{26}$. The literature is poor in this area. Hong et al. reported a positive SVIN in $71 \%$ of MD subjects beating toward the lesion side in $27 \%$ of cases ${ }^{26}$. Dumas et al. described a SVIN in $71 \%$ of MD patients (most observed in a pre-attack or a period close to a recent attack) with modified caloric test results in $64 \%{ }^{12}$. We detected a lower percentage of positive patients with this test; however, it should be noted that previous investigations included patients studied immediately after a vertigo attack.

Finally, little has been published about positional tests in MD. In our cohort, 198 patients (38.7\%) showed a positive positional test, detecting apogeotropic nystagmus in 169 of them when lying on the affected side. In 29 cases (5.6\%), a smooth bipositional apogeotropic nystagmus was detected, without vertigo. Several hypotheses can be made on this finding. It could be hypothesised that the presence of a small otoconial mass in a lateral canal, unable to provoke a consistent nystagmus (even if patients denied positional nystagmus in the previous days), may be the causal factor of the finding, although a "heavy or light cupola" mechanism cannot be excluded. Finally, since a consistent part of our sample was composed of migraineurs and positional nystagmus is the most common finding in vestibular migraine (VM), it could be assumed that a proportion might experience attacks of both hydrops and VM, and the clinical finding may be related to the latter ${ }^{27}$. The increased rate of positional nystagmus in the subsample of migraineurs seems to support this hypothesis.

Data from our study support the hypothesis that SVIN has a higher sensitivity to detect a vestibular deficit in MD outside a vertigo attack, while HIT is more frequently normal; the finding is not inconsistent with the possibility that a discrepancy between the 2 tests may be useful in the diagnostic pathway. Further studies can assess if a dissociation between the 2 tests may be a peculiar characteristic of MD. Moreover, SVIN mainly detect a deficit of the lateral canal function; other tests, ocular and cervical VEMPs, are promising in studying macular function, above all when performed with sounds at different frequencies and studying the tuning curve of responses, thus allowing a mapping of all parts of the inner ear ${ }^{28,29}$.

Some weak points in our investigation should be underlined. For example, we were unable to retrieve data about all comorbidities or about the number of crises in the last 6 months. On the other hand, even though further studies are needed, our data are not inconsistent with the hypothesis that skull vibration can be easy to perform and fast to orient the clinician towards diagnosis of a hydropic form.

\section{Conclusions}

Thorough clinical history and careful bedside vestibular examination can orientate the clinician's suspicions towards MD, thus guiding and confirming definite diagnosis.

\section{References}

Sajjadi H, Paparella MM. Meniere's disease. Lancet 2008;372:40614. https://doi.org/10.1016/S0140-6736(08)61161-7

2 Merchant SN, Adams JC, Nadol JB Jr. Pathophysiology of Meniere's syndrome: are symptoms caused by endolymphatic hydrops? Otol Neurotol 2005;26:74-81. https://doi.org/10.1097/00129492200501000-00013

3 Ito T, Inui H, Miyasaka T, et al. Endolymphatic volume in patients with meniere's disease and healthy controls: three-dimensional analysis with magnetic resonance imaging. Laryngoscope Investig Otolaryngol 2019;4:653-8. https://doi.org/10.1002/lio2.313

4 Frejo L, Martin-Sanz E, Teggi R, et al. Extended phenotype and clinical subgroups in unilateral Meniere disease: a cross-sectional study with cluster analysis. Clin Otolaryngol 2017;42:1172-80. https://doi. org/10.1111/coa.12844

5 Requena T, Espinosa-Sanchez JM, Cabrera S, et al. Familial clustering and genetic heterogeneity in Meniere's disease. Clin Genet 2014;85:245-52. https://doi.org/10.1111/cge.12150

6 Teggi R, Carpini SD, Zagato L. Endolymphatic hydrops and ionic transporters: genetic and biohumoral aspects. J Neurol 2019;266(Suppl 1):47-51. https://doi.org/10.1007/s00415-019-09399-6 
7 Lopez-Escamez JA, Carey J, Chung WH, et al. Diagnostic criteria for Menière's disease. J Vestib Res 2015;25:1-7. https://doi.org/10.3233/ VES-150549

8 Radtke A, Lempert T, Gresty MA, et al. Migraine and Ménière's disease: is there a link? Neurology 2002;59:1700-4. https://doi. org/10.1212/01.wnl.0000036903.22461.39

9 Kim SH, Kim JY, Lee HJ, et al. Autoimmunity as a candidate for the etiopathogenesis of Meniere's disease: detection of autoimmune reactions and diagnostic biomarker candidate. PLoS One 2014;9:e111039. https://doi.org/10.1371/journal.pone.0111039.

10 Headache Classification Committee of the International Headache Society (IHS). The International Classification of Headache Disorders, $3^{\text {rd }}$ edition (beta version). Cephalalgia 2013;33:629-808. https:// doi.org/10.1177/0333102413485658

11 Teggi R, Zagato L, Delli Carpini S, et al. Genetics of ion homeostasis in Ménière's Disease. Eur Arch Otorhinolaryngol 2017;274:757-63. https://doi.org/10.1007/s00405-016-4375-9

12 Dumas G, Curthoys IS, Lion A, et al. The skull vibration-induced nystagmus test of vestibular function - a review. Front Neurol 2017;8:41. https://doi.org/10.3389/fneur.2017.00041

13 Versino M, Colagiorgio P, Sacco S, et al. Artifact avoidance for head impulse testing. Clin Neurophysiol 2014;125:1071-3. https://doi. org/10.1016/j.clinph.2013.09.024

14 Woldeamanuel YW, Cowan RP. Migraine affects 1 in 10 people worldwide featuring recent rise: A systematic review and meta-analysis of community-based studies involving 6 million participants. J Neurol Sci 2017;372:307-15. https://doi.org/10.1016/j.jns.2016.11.071

15 Gürkov R, Jerin C, Flatz W, et al. Clinical manifestations of hydropic ear disease (Menière's) [published correction appears in Eur Arch Otorhinolaryngol 2019;276:619-20]. Eur Arch Otorhinolaryngol 2019;276:27-40. https://doi.org/10.1007/s00405-018-5157-3

16 Frejo L, Giegling I, Teggi R, et al. Genetics of vestibular disorders: pathophysiological insights. J Neurol 2016;263(Suppl 1):S45-53. https://doi.org/10.1007/s00415-015-7988-9

17 Hietikko E, Kotimäki J, Sorri M, et al. High incidence of Meniere-like symptoms in relatives of Meniere patients in the areas of Oulu University Hospital and Kainuu Central Hospital in Finland. Eur J Med Genet 2013;56:279-85. https://doi.org/10.1016/j.ejmg.2013.03.010

18 Frejo L, Soto-Varela A, Santos-Perez S, et al. Clinical subgroups in bilateral Meniere disease. Front Neurol 2016;7:182. https://doi. org/10.3389/fneur.2016.00182
19 Fattori B, Nacci A, Dardano A, et al. Possible association between thyroid autoimmunity and Menière's disease. Clin Exp Immunol 2008;152:28-32. https://doi.org/10.1111/j.1365-2249.2008.03595.x

20 Girasoli L, Cazzador D, Padoan R, et al. Update on vertigo in autoimmune disorders, from diagnosis to treatment. J Immunol Res 2018;26:5072582. https://doi.org/10.1155/2018/5072582

21 Oberman BS, Patel VA, Cureoglu S, et al. The aetiopathologies of Ménière's Disease: a contemporary review. Acta Otorhinolaryngol Ital 2017;37:250-63. https://doi.org/10.14639/0392-100X-79.

22 Blödow A, Pannasch S, Walther LE. Detection of isolated covert saccades with the video head impulse test in peripheral vestibular disorders. Auris Nasus Larynx 2013;40:348-51. https://doi.org/10.1016/j. anl.2012.11.002

23 Heuberger M, Sağlam M, Todd NS, et al. Covert anti-compensatory quick eye movements during head impulses. PLoS One 2014;9:e93086. https://doi.org/10.1371/journal.pone.0093086

24 McGarvie LA, Curthoys IS, MacDougall HG, et al. What does the dissociation between the results of video head impulse versus caloric testing reveal about the vestibular dysfunction in Ménière's disease? Acta Otolaryngol 2015;135:859-65. https://doi.org/10.3109/0001648 9.2015 .1015606

25 Ohki M, Murofushi T, Nakahara H, et al. Vibration-induced nystagmus in patients with vestibular disorders. Otolaryngol Head Neck Surg 2003;129:255-8. https://doi.org/10.1016/S0194-5998(03)00529-1

26 Hong SK, Koo JW, Kim JS, et al. Implication of vibration induced nystagmus in Meniere's disease. Acta Otolaryngol Suppl 2007;(558):128-31. https://doi.org/10.1080/03655230701625019

27 Teggi R, Colombo B, Albera R, et al. Clinical features, familial history, and migraine precursors in patients with definite vestibular migraine: the VM-Phenotypes projects. Headache 2018;58:534-44. https://doi.org/10.1111/head.13240

28 Scarpa A, Gioacchini FM, Cassandro E, et al. Clinical application of cVEMPs and oVEMPs in patients affected by Ménière's disease, vestibular neuritis and benign paroxysmal positional vertigo: a systematic review. Acta Otorhinolaryngol Ital 2019;39:298-307. https://doi. org/10.14639/0392-100X-2104

29 Sobhy OA, Elmoazen DM, Abd-Elbaky FA. Towards a new staging of Meniere's disease: a vestibular approach. Acta Otorhinolaryngol Ital 2019;39:419-28. https://doi.org/10.14639/0392-100X-2461 